\title{
1 Comparative Proteomics on Deep-sea Amphipods after in situ Copper
}

\section{Exposure}

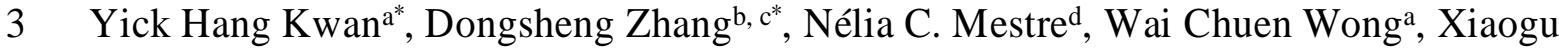

4 Wang ${ }^{\mathrm{b}, \mathrm{c}}$, Bo Lu ${ }^{\mathrm{b}, \mathrm{c}}$, Chunsheng Wang ${ }^{\mathrm{b}, \mathrm{c}}$, Pei-Yuan Qian ${ }^{\mathrm{a}}$, Jin Sun ${ }^{\mathrm{a} \#}$

5

6 a Department of Ocean Science, Division of Life Science and Hong Kong Branch of the

$7 \quad$ Southern Marine Science and Engineering Guangdong Laboratory, The Hong Kong

8 University of Science and Technology, Hong Kong, China

9 b Second Institute of Oceanography, Ministry of Natural Resources, Hangzhou, China

10 c Key Laboratory of Marine Ecosystem and Biochemistry, State Oceanic Administration,

11 Hangzhou, China

12 d CIMA - Centro de Investigação Marinha e Ambiental, Universidade do Algarve, Campus de 13 Gambelas, 8005-139, Faro, Portugal

14

$15 \quad{ }^{*}$ Contributed equally

$16 \quad{ }^{\#}$ Corresponding author

17

18 Supporting Information:

1914 pages (including cover)

201 sections (Part I)

214 tables (S1, S2, S3 and S4)

223 figure (S1, S2 and S3) 


\section{Part I. Additional details of method and materials}

\section{Treatment of samples for ICP-MS}

The stomach was freeze-dried for 24 hours by the manifold freeze-drier prior to digestion in $1 \mathrm{~mL} 70 \% \mathrm{HNO}_{3}$ on an aluminum heating block digestion at $80^{\circ} \mathrm{C}$ for 12 hours. After diluting the final volume to $2.5 \mathrm{~mL}$, the copper concentration in each digested sample was determined by ICP-MS.

\section{Whole protein extraction treatment}

The body tissue from each individual were first fixed in a lysis buffer (8M Urea; 20mM Tris-

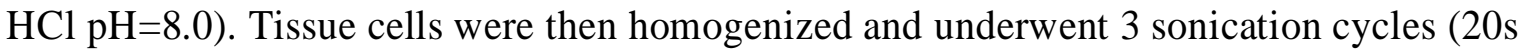
sonication, 20s pause; 75\% amp) using Q125 Sonicator (Qsonica, CT, USA), followed by centrifugation $\left(15000 \mathrm{~g}, 4^{\circ} \mathrm{C}, 10 \mathrm{mins}\right)$. The supernatant was used in the Methanol/Chloroform protein precipitation for purifying the extracted protein from the tissue $^{1}$.

\section{TMT-labelling operation details}

The dried protein pellets were then re-dissolved in the lysis buffer mentioned above, approximately $30 \mu \mathrm{g}$ of protein from each sample, and then used in reduction and alkylation of extracted protein by incubating $5 \mu \mathrm{L}$ of $50 \mathrm{mM}$ Tetraethylammonium bromide (TEAB) in the sample for 1 hour at $55^{\circ} \mathrm{C}$, followed by adding in $7 \mu \mathrm{L}$ of $375 \mathrm{mM}$ iodoacetamide (IAA) to samples and 30 minutes incubation in completely dark condition and at room temperature ${ }^{2}$. $1 \mu \mathrm{g}$ of Sequencing Grade Modified Trypsin (Promega, WI, USA) was added to the sample solution, maintaining trypsin ratio and protein ratio at 1:30. The protein sample was digested for 14 hours at $37^{\circ} \mathrm{C}$. The digested protein sample was then desalted by applying the $\mathrm{C} 18$ Cartridge Solid Phase Extracting (SPE) from Sep-Pak (Waters, MA, USA). 
A C18 column (Water BEH C18 4.6x250 mm, $5 \mu \mathrm{m}$ ) was used to perform HPLC fractionation of the TMT labelled mixed peptide on a Rigol L3000 HPLC operating rate $(1 \mathrm{~mL} / \mathrm{min})$, fixing the column in the oven at $50^{\circ} \mathrm{C}^{3}$. Two mobile phase $\mathrm{A}$ and $\mathrm{B}$, with fixed pH 10.0 by adding ammonium hydroxide, was $2 \%$ ACN and $98 \%$ ACN respectively as to establish an eluting gradient. Solvent gradient was developed in the following manner: 5 mins of $3 \%$ B, 0.1 min of 3-8\% B, 11.9 mins of $8-18 \%$ B, 11 min of $18-32 \%$ B, 7 mins of 32$45 \%$ B, 3 mins of $45-80 \%$ B, 5 mins of $80-85 \%$ B, 0.1 mins of $80-5 \%$ B and 6.9 mins of $5 \%$ B. The sampled peptides were observed at UV $214 \mathrm{~nm}$. At each 60 seconds interval, the eluted samples were collected and normalized into 15 fractions based on the fraction UV absorbance value. Prior to further experimental procedures, these samples were reconditioned in $0.1 \%$ formic acid (FA) after being completely dried under vacuum.

60

The Data-dependent acquisition (DDA) mode was engaged by EASY-nLCTM 1200 UHPLC system (ThermoFisher, U.S.A.) coupled with an Orbitrap Q Exactive HF-X mass spectrometer (ThermoFisher, U.S.A.) to achieve shotgun proteomics analyses ${ }^{4}$. Acclaim PepMap100 C18 Nano-Trap column $(2 \mathrm{~cm} \times 100 \mu \mathrm{m}, 5 \mu \mathrm{m})$ was used to inject approximately $2 \mu \mathrm{g}$ of peptide in each fraction which was re-constituted in $0.1 \%$ FA. By adopting the flow rate of $600 \mathrm{~nL} / \mathrm{min}$ of $0.1 \%$ FA in $80 \% \mathrm{ACN}$ and $0.1 \%$ FA in MilliQ water, which accordingly were eluent A and B, in the linear gradient of 120 minutes for separation of TMT 10-plex peptides on a Reprosil-Pur 120 C18-AQ analytical column $(15 \mathrm{~cm} \times 150 \mu \mathrm{m}, 1.9 \mu \mathrm{m})$. Solvent gradient was developed in the following manner: 2 mins of 5-10\% B, 105 min of 10$40 \%$ B, 5 mins of $40-50 \%$ B, 3 min of $50-90 \%$ B, 5 mins of and $90-100 \%$ B. 
72 Positive polarity mode was executed in the mass spectrometer in $320^{\circ} \mathrm{C}$ capillary temperature

73 and $2.3 \mathrm{kV}$ spray voltage for DDA. At 20 ms maximum ion injection time and $3 \times 10^{6}$

74 automatic gain control (AGC) target value combined with 60,000 (at $200 \mathrm{~m} / \mathrm{z}$ ) resolution

75 captured the full MS scan, providing a 45,000 resolution (at $200 \mathrm{~m} / \mathrm{z}$ ) of 40 of most abundant

76 precursor ions filtered from the higher energy collisional dissociation (HCD) fragment

77 analysis for the samples (setting: $45 \mathrm{~ms}$ maximum ion injection time, $1 \times 10^{5}$ AGC target value,

78 60s dynamic exclusion parameter, 32\% normalized collison energy and $8.3 \times 10^{3}$ intensity

79 threshold).

80

\section{$81 \quad$ qPCR operation details}

82 The qPCR mix for each well was prepared by adding $5 \mu$ of SYBR green PCR Master Mix

83 (Roche Diagnostics GmbH), $2 \mu 1$ of cDNA, $1 \mu$ of the forward primers, $1 \mu 1$ of reverse

84 primers and $2 \mu \mathrm{l}$ of PCR-grade water. 3 technical replicates of each sample were used to

85 eliminate the possible experimental errors. LightCycler 480 Instrument II was then

86 programmed to: first $95^{\circ} \mathrm{C}$ for 10 mins, then $95^{\circ} \mathrm{C}$ for $30 \mathrm{~s}, 60^{\circ} \mathrm{C}$ for $30 \mathrm{~s}$ and $72^{\circ} \mathrm{C}$ for $30 \mathrm{~s}$ for

8745 cycles. A negative control, where PCR-grade water was added instead of cDNA was

88 added to ensure the detection of the result was valid. 


\section{References:}

90 1. Wessel, D. m.; Flügge, U., A method for the quantitative recovery of protein in dilute 91 solution in the presence of detergents and lipids. Anal. Biochem. 1984, 138, (1), 141-143.

92 2. Sun, J.; Zhang, H.; Wang, H.; Heras, H.; Dreon, M. S.; Ituarte, S.; Ravasi, T.; Qian, P.-Y.; Qiu, J.-W., First proteome of the egg perivitelline fluid of a freshwater gastropod with aerial oviposition. J. Proteome Res. 2012, 11, (8), 4240-4248.

3. Wu, J.; An, Y.; Pu, H.; Shan, Y.; Ren, X.; An, M.; Wang, Q.; Wei, S.; Ji, J.,

Enrichment of serum low-molecular-weight proteins using C18 absorbent under urea/dithiothreitol denatured environment. Anal. Biochem. 2010, 398, (1), 34-44.

4. Wu, J.; Xie, X.; Liu, Y.; He, J.; Benitez, R.; Buckanovich, R. J.; Lubman, D. M., Identification and confirmation of differentially expressed fucosylated glycoproteins in the serum of ovarian cancer patients using a lectin array and LC-MS/MS. J. Proteome Res. 2012, 11, (9), 4541-4552.

5. $\quad$ Gismondi, E.; Thomé, J.-P.; Urien, N.; Uher, E.; Baiwir, D.; Mazzucchelli, G.; De

103 Pauw, E.; Fechner, L. C.; Lebrun, J. D., Ecotoxicoproteomic assessment of the functional

104 alterations caused by chronic metallic exposures in gammarids. Environ. Pollut. 2017, 225,

$105 \quad 428-438$.

106 6. Gouveia, D.; Chaumot, A.; Charnot, A.; Queau, H.; Armengaud, J.; Almunia, C.;

107 Salvador, A.; Geffard, O., Assessing the relevance of a multiplexed methodology for

108 proteomic biomarker measurement in the invertebrate species Gammarus fossarum: A

109 physiological and ecotoxicological study. Aquat. Toxicol. 2017, 190, 199-209.

110 7. Lin, L.; Xu, M.; Mu, H.; Wang, W.; Sun, J.; He, J.; Qiu, J.-W.; Luan, T., Quantitative

111 proteomic analysis to understand the mechanisms of zinc oxide nanoparticle toxicity to

112 Daphnia pulex (Crustacea: Daphniidae):: Comparing with Bulk Zinc Oxide and Zinc salt.

113 Environ. Sci. Technol. 2019. 
114 8. Poynton, H. C.; Zuzow, R.; Loguinov, A. V.; Perkins, E. J.; Vulpe, C. D., Gene

115 expression profiling in Daphnia magna, part II: validation of a copper specific gene

116 expression signature with effluent from two copper mines in California. Environ. Sci.

117 Technol. 2008, 42, (16), 6257-6263.

118 9. Poynton, H. C.; Loguinov, A. V.; Varshavsky, J. R.; Chan, S.; Perkins, E. J.; Vulpe,

119 C. D., Gene expression profiling in Daphnia magna part I: concentration-dependent profiles 120 provide support for the no observed transcriptional effect level. Environ. Sci. Technol. 2008, 121 42, (16), 6250-6256. 
Table S1. The total number of identified proteins annotated to UniPort/NCBInr/KEGG/GO.

\begin{tabular}{ccccc} 
& UniPort & NCBInr & KEGG & GO \\
\hline All Identified Proteins (2937*) & 2432 & 2796 & 1748 & 1785 \\
High Vs Control (67) & 49 & 60 & 28 & 35 \\
Low Vs Control (67) & 48 & 56 & 31 & 26
\end{tabular}

*The number in brackets of the first column indicated the total number of identified proteins in that particular group. 
Table S2. Differentially expressed proteins and their fold change level in Abyssorchomene distinctus, after in situ copper exposure.

\begin{tabular}{|c|c|c|c|c|c|c|c|}
\hline \multirow{2}{*}{$\begin{array}{l}\text { Protein description } \\
\text { Fold-change }\end{array}$} & \multirow{2}{*}{$\begin{array}{l}\text { Up/Down } \\
\text { regulated }\end{array}$} & \multicolumn{2}{|c|}{$\begin{array}{l}\text { Low Vs } \\
\text { control }\end{array}$} & \multicolumn{2}{|c|}{$\begin{array}{l}\text { High Vs } \\
\text { control }\end{array}$} & \multirow{2}{*}{$\begin{array}{c}\text { Dose } \\
\text { dependent }\end{array}$} & \multirow[t]{2}{*}{ P-value } \\
\hline & & \multicolumn{4}{|c|}{ Metabolism } & & \\
\hline Exonuclease 3'-5' domain-containing protein 2 & $\uparrow$ & 4.26 & 4.96 & 5.19 & 3.80 & $\mathrm{Y}$ & 0 \\
\hline RNA-directed DNA polymerase from mobile element jockey & $\uparrow$ & 2.07 & 1.93 & 2.82 & 0.31 & $\mathrm{Y}$ & $5.68 \times 10^{-5}$ \\
\hline Macrophage receptor MARCO & $\uparrow$ & 1.87 & 0.61 & 2.34 & 1.08 & $\mathrm{Y}$ & $1.48 \times 10^{-3}$ \\
\hline GMP synthase & $\uparrow$ & 2.54 & 2.71 & 2.10 & 0.52 & $\mathrm{~N}$ & $1.08 \times 10^{-3}$ \\
\hline Cuticle protein & $\uparrow$ & 2.44 & 2.03 & 2.01 & 0.98 & $\mathrm{~N}$ & $5.74 \times 10^{-3}$ \\
\hline Larval cuticle protein & $\uparrow$ & 1.55 & 0.42 & 1.88 & 0.84 & $\mathrm{Y}$ & $6.93 \times 10^{-3}$ \\
\hline $\begin{array}{l}\text { Guanosine-3',5'-bis(diphosphate) 3'-pyrophosphohydrolase } \\
\text { MESH1 }\end{array}$ & $\uparrow$ & 1.23 & 0.04 & 1.85 & 0.61 & $\mathrm{Y}$ & $6.48 \times 10^{-3}$ \\
\hline 60S ribosomal protein L18a & $\uparrow$ & 1.88 & 1.24 & 1.77 & 0.45 & $\mathrm{~N}$ & $7.67 \times 10^{-3}$ \\
\hline NADH dehydrogenase & $\uparrow$ & 1.63 & 1.06 & 1.75 & 0.10 & $\mathrm{Y}$ & $4.15 \times 10^{-3}$ \\
\hline recombinase & $\uparrow$ & 0.67 & 0.33 & 1.71 & 0.03 & $\mathrm{~N}$ & $3.58 \times 10^{-3}$ \\
\hline RNA-dependent RNA polymerase & $\uparrow$ & 1.17 & 1.44 & 1.57 & 0.99 & $\mathrm{Y}$ & $2.56 \times 10^{-3}$ \\
\hline Venom metalloproteinase 3 & $\downarrow$ & 0.44 & 0.15 & 0.96 & 1.01 & $\mathrm{~N}$ & $9.09 \times 10^{-4}$ \\
\hline Actin-related protein 10 & $\downarrow$ & 0.51 & 0.19 & 0.91 & 0.62 & $\mathrm{~N}$ & $2.90 \times 10^{-3}$ \\
\hline CD63 antigen-like & $\downarrow$ & 0.49 & 0.18 & 0.87 & 0.41 & $\mathrm{~N}$ & $1.02 \times 10^{-3}$ \\
\hline Proteasome subunit beta type- 5 & $\downarrow$ & 0.57 & 0.07 & 0.72 & 0.14 & $\mathrm{~N}$ & $9.38 \times 10^{-3}$ \\
\hline Polypeptide N-acetylgalactosaminyltransferase 5 & $\downarrow$ & 0.61 & 0.22 & 0.72 & 0.31 & $\mathrm{~N}$ & $8.52 \times 10^{-3}$ \\
\hline Receptor expression-enhancing protein 5 & $\downarrow$ & 0.49 & 0.05 & 0.71 & 0.31 & $\mathrm{~N}$ & $1.48 \times 10^{-3}$ \\
\hline cubilin-like & $\downarrow$ & 0.53 & 0.46 & 0.70 & 0.26 & $\mathrm{~N}$ & $1.42 \times 10^{-3}$ \\
\hline perlucin-like protein & $\downarrow$ & 0.32 & 0.21 & 0.70 & 0.11 & $\mathrm{~N}$ & $5.68 \times 10^{-5}$ \\
\hline Failed axon connections homolog & $\downarrow$ & 0.56 & 0.07 & 0.69 & 0.13 & $\mathrm{~N}$ & $9.09 \times 10^{-3}$ \\
\hline Minor histocompatibility antigen $\mathrm{H} 13$ & $\downarrow$ & 0.54 & 0.22 & 0.68 & 0.25 & $\mathrm{~N}$ & $4.32 \times 10^{-3}$ \\
\hline Chymotrypsin BI & $\downarrow$ & 0.41 & 0.18 & 0.65 & 0.42 & $\mathrm{~N}$ & $2.73 \times 10^{-3}$ \\
\hline Facilitated glucose transporter protein 1 & $\downarrow$ & 0.63 & 0.40 & 0.62 & 0.33 & Y & $5.23 \times 10^{-3}$ \\
\hline transmembrane protease serine 9-like & $\downarrow$ & 0.38 & 0.20 & 0.60 & 0.14 & $\mathrm{~N}$ & $5.28 \times 10^{-3}$ \\
\hline Protein NPC2 homolog & $\downarrow$ & 0.48 & 0.27 & 0.58 & 0.08 & $\mathrm{~N}$ & $4.03 \times 10^{-3}$ \\
\hline Kelch-like ECH-associated protein 1 & $\downarrow$ & 0.47 & 0.06 & 0.54 & 0.00 & $\mathrm{~N}$ & $9.38 \times 10^{-3}$ \\
\hline Chitotriosidase-1 & $\downarrow$ & 0.54 & 0.03 & 0.54 & 0.17 & $\mathrm{~N}$ & $7.61 \times 10^{-3}$ \\
\hline Glutathione peroxidase & $\downarrow$ & 0.46 & 0.06 & 0.52 & 0.21 & $\mathrm{~N}$ & $8.41 \times 10^{-3}$ \\
\hline putative LWS opsin & $\downarrow$ & 0.58 & 0.17 & 0.49 & 0.16 & $\mathrm{Y}$ & $1.48 \times 10^{-3}$ \\
\hline lectin domain family 4 member $\mathrm{F}$ & $\downarrow$ & 0.35 & 0.12 & 0.47 & 0.15 & $\mathrm{~N}$ & $3.18 \times 10^{-3}$ \\
\hline probable N-acetyltransferase CML3 & $\downarrow$ & 0.45 & 0.12 & 0.47 & 0.20 & $\mathrm{~N}$ & $9.09 \times 10^{-4}$ \\
\hline Carboxypeptidase B & $\downarrow$ & 0.37 & 0.15 & 0.46 & 0.14 & $\mathrm{~N}$ & $2.90 \times 10^{-3}$ \\
\hline chymotrypsin A-like & $\downarrow$ & 0.46 & 0.26 & 0.41 & 0.08 & $\mathrm{Y}$ & $6.76 \times 10^{-3}$ \\
\hline Acidic mammalian chitinase & $\downarrow$ & 0.28 & 0.03 & 0.26 & 0.03 & $\mathrm{Y}$ & $5.68 \times 10^{-5}$ \\
\hline \multicolumn{8}{|c|}{ Energy } \\
\hline Histidine--tRNA ligase, cytoplasmic & $\uparrow$ & 2.14 & 1.75 & 3.20 & 2.32 & $\mathrm{Y}$ & $2.84 \times 10^{-4}$ \\
\hline ATP synthase subunit alpha, mitochondrial & $\uparrow$ & 4.49 & 5.61 & 2.95 & 1.03 & $\mathrm{~N}$ & $1.14 \times 10^{-4}$ \\
\hline ATP-binding cassette sub-family F member 3 & $\uparrow$ & 2.05 & 0.36 & 1.37 & 0.49 & $\mathrm{~N}$ & $1.36 \times 10^{-3}$ \\
\hline Cytochrome c oxidase subunit 5B, mitochondrial & $\uparrow$ & 1.80 & 0.46 & 1.10 & 0.08 & $\mathrm{~N}$ & $6.93 \times 10^{-3}$ \\
\hline \multicolumn{8}{|c|}{ Protein synthesis } \\
\hline Peptidyl-prolyl cis-trans isomerase, rhodopsin-specific isozyme & $\uparrow$ & 1.41 & 0.55 & 2.06 & 1.40 & $\mathrm{Y}$ & $3.47 \times 10^{-3}$ \\
\hline Protein odr-4 homolog & $\uparrow$ & 1.78 & 1.40 & 1.80 & 0.65 & $\mathrm{Y}$ & $6.08 \times 10^{-3}$ \\
\hline poly(U)-specific endoribonuclease-like & $\downarrow$ & 0.38 & 0.10 & 0.43 & 0.06 & $\mathrm{~N}$ & $1.48 \times 10^{-3}$ \\
\hline Di-N-acetylchitobiase & $\downarrow$ & 0.36 & 0.07 & 0.37 & 0.15 & $\mathrm{~N}$ & $9.09 \times 10^{-4}$ \\
\hline \multicolumn{8}{|c|}{ Protein Fate } \\
\hline Vascular endothelial growth factor B & $\uparrow$ & 1.19 & 0.46 & 1.78 & 0.42 & $\mathrm{Y}$ & $6.71 \times 10^{-3}$ \\
\hline gamma-interferon-inducible lysosomal thiol reductase & $\downarrow$ & 0.48 & 0.09 & 0.70 & 0.22 & $\mathrm{~N}$ & $2.05 \times 10^{-3}$ \\
\hline Translationally-controlled tumor protein homolog & $\downarrow$ & 0.63 & 0.27 & 0.66 & 0.40 & $\mathrm{~N}$ & $8.75 \times 10^{-3}$ \\
\hline heat shock protein 70 & $\downarrow$ & 0.45 & 0.04 & 0.56 & 0.19 & $\mathrm{~N}$ & $9.09 \times 10^{-3}$ \\
\hline transmembrane protein 53 & $\downarrow$ & 0.90 & 0.89 & 0.51 & 0.50 & $\mathrm{Y}$ & $6.25 \times 10^{-4}$ \\
\hline Cathepsin D & $\downarrow$ & 0.47 & 0.14 & 0.40 & 0.13 & $\mathrm{Y}$ & $3.41 \times 10^{-3}$ \\
\hline \multicolumn{8}{|c|}{ Cellular Transport, Transport Facilitation and Transport Routes } \\
\hline $\mathrm{Na}^{+} / \mathrm{K}^{+}$-transporting ATPase subunit alpha & $\uparrow$ & 2.60 & 1.83 & 6.72 & 7.56 & $\mathrm{Y}$ & 0 \\
\hline Golgi to ER traffic protein 4 homolog & $\downarrow$ & 0.52 & 0.10 & 0.57 & 0.17 & $\mathrm{~N}$ & $2.78 \times 10^{-3}$ \\
\hline
\end{tabular}


$0.64 \quad 0.45$

$\begin{array}{ccc}\downarrow & 0.64 \quad 0 . \\ \text { Protein with Binding Function }\end{array}$

Zinc finger CCHC domain-containing protein

Ferritin

Cleavage stimulation factor subunit 2

Oligoribonuclease, mitochondrial

PDZ domain-containing protein GIPC1

Ankyrin repeat and MYND domain-containing protein 2

YEATS domain-containing protein 2-like

Golgi phosphoprotein 3 homolog sauron

Elongation factor 1-alpha

Zonadhesin

Protein mago nashi homolog

C-type lectin mannose-binding isoform

Probable hemoglobin and hemoglobin-haptoglobin-binding protein 3

THO complex subunit 6 homolog

39S ribosomal protein L30, mitochondrial

Transmembrane protein 205

Anti-lipopolysaccharide factor

titin isoform $\mathrm{X} 1$

Laminin subunit gamma-1

mucin-19-like isoform X1

Cadherin-like and PC-esterase domain-containing protein 1

Protein Skeletor, isoforms B/C

Kelch-like protein 24

Defense protein l(2)34Fc

Blastula protease 10

Transmembrane protein 147

Blastula protease 10

Mediator of RNA polymerase II transcription subunit 15

Hsp70-binding protein 1

Protein canopy 4

protein catecholamines up-like

unknown protein

uncharacterized protein LOC108673035 isoform

uncharacterized protein LOC108678333

unknown protein

uncharacterized protein LOC100119467

unknown protein

uncharacterized protein LOC108865118, partial

uncharacterized protein LOC108673361

hypothetical protein AWC38_SpisGene3258

unknown protein

Collagen alpha-1(IV) chain

unknown protein

uncharacterized protein LOC108674692

unknown protein

unknown protein

unknown protein

unknown protein

unknown protein

unknown protein

unknown protein

uncharacterized protein LOC108674485

uncharacterized protein LOC108673521

unknown protein

\section{$5.04 \quad 5.78$}

0.75

1.49

3.38

2.06

2.65

1.50

2.16

1.77

1.98

0.55

0.47

0.96

$\begin{array}{cc}\downarrow & 0.51 \\ \text { Biological Function }\end{array}$

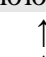

$\uparrow$

\subsection{9}

\subsection{1}

2.95

1.46

2.14

2.32

0.51

0.49

0.56

0.51

0.52

0.61

0.56

0.56

Biological Regulation

$3.82 \quad 4.31$

$\begin{array}{ll}\uparrow & 3.82 \\ \uparrow & 2.90\end{array}$

2.90
2.03

0.50

Others or unknown proteins

$\begin{array}{lll}\uparrow & 5.71 \quad 8.27\end{array}$

$2.72 \quad 3.24$

3.70

1.63

2.71

1.80

1.71

2.20

1.91

2.41

1.95

0.36

2.22

1.99

0.55

0.51

0.87

0.58

0.73

0.33

0.39

0.40

0.57
3.20

0.23

0.40

0.14

$\begin{array}{ll}7.99 & 5.09\end{array}$

$3.85 \quad 5.26$

0.41

3.56

3.12

2.78

2.70

2.71

2.11

1.61

2.67

1.86

1.85

1.03
0.73

1.77

0.09

0.02

1.46

0.74

0.66

0.58

0.07

0.41

2.89

1.80
0.41

1.39

0.80

0.22

0.08

0.16

0.10

0.12

0.20

0.13

0.06

2.89

1.93

1.50

1.41

0.91

0.88

0.85

0.71

0.64

0.61

0.59

0.54

3.12
2.35

2.35
1.98

0.68

5.18

3.86

3.29

3.32

2.62

3.18

2.53

0.83

0.95

2.48

2.06

0.99

2.01

1.91

1.81

1.81

0.25

0.03

1.65

1.51

2.02

1.34

1.16

0.94

1.05

0.10

0.84

0.17

0.65

0.35

0.06

0.07

0.61

0.59

0.58

0.08

0.53

0.09

0.50

0.06

0.25

0.44

0.20
1.81

1.38

1.84

0.78

1.52

1.10

0.48

0.62

0.24

0.26

0.07

0.03

\subsection{0}

0.89

0.36

0.47

0.40

0.53

0.60

0.49

0.19

0.24

0.11

0.28

0.05

1.03

1.05

0.40

0.08

6.35

5.31

1.44

2.15

2.26

2.60

1.33

0.58

0.94

0.63

0.44

1.22

0.11

0.31

0.13

0.22

0.25

0.07

0.03

0.26

0.22

0.07

0.06

Y

$1.19 \times 10^{-3}$

$\mathrm{Y}$
$\mathrm{N}$

Y

N

Y

$\mathrm{Y}$

$\mathrm{N}$

$\mathrm{N}$

N

$\mathrm{N}$ 
Table S3a. The GO enriched up-regulated proteins between Low Versus Control group.

category Term (GO number) and proteins included

$\mathrm{MF}$

Ion binding(0043167): ATP synthase subunit alpha, Zinc finger CCHC domain-containing protein, ATP-binding cassette sub-family F member 3 and $\mathrm{Na}^{+} / \mathrm{K}^{+}$-transporting ATPase subunit alpha nucleotide binding(0000166):

MF ATP synthase subunit alpha, ATP-binding cassette sub-family F member 3 and $\mathrm{Na}^{+} / \mathrm{K}^{+}$-transporting ATPase subunit alpha

Table S3b. The GO enriched down-regulated proteins between Low and Control group.

Proteolysis (0006508): chymotrypsin-like protein, proteasome subunit beta type-5, venom

BP metalloproteinase 3-like, transmembrane protease serine 9-like, chymotrypsin A-like, blastula protease 10-like and carboxypeptidase B-like

BP Chitin catabolic process (0006032): chitinase 3 and di-N-acetylchitobiase precursor Transmembrane transport (0055085):

facilitated glucose transporter member 1-like isoform X3 and protein catecholamines up-like

Serine-type endopeptidase activity (0004252): transmembrane protease serine 9-like, chymotrypsin Alike and chymotrypsin-like protein

Chitinase activity (0004568): chitinase 3 and di-N-acetylchitobiase precursor

MF fold-

change

$p$-value

fold- $\quad p$-value

change

4.5

$3.52 \times 10^{-2}$

28

$3.79 \times 10^{-2}$

14.6

$5.74 \times 10^{-6}$

45.4

$1.55 \times 10^{-3}$

$2.53 \times 10^{-2}$

$5.77 \times 10^{-4}$

45.4

$1.55 \times 10^{-3}$

18.1 
Table S4. A summary of the GO enriched proteins found in this study and in other metal toxicity from the literature. (“ $\uparrow$ ” indicates up-regulation, “ $\downarrow ”$ indicates down-regulation and “-” indicates the regulations was not specific in the references studies.)

\begin{tabular}{|c|c|c|c|c|c|c|c|}
\hline \multirow[b]{2}{*}{ Proteins } & \multirow[t]{2}{*}{$\begin{array}{l}\text { In-situ in deep-sea } \\
\text { (this study) }\end{array}$} & \multirow[t]{2}{*}{$\begin{array}{l}\text { Bourbre River, } \\
\text { assimilated in } \\
\text { Laboratory }\end{array}$} & \multirow[t]{2}{*}{$\begin{array}{c}\text { Bourbre River, } \\
\text { assimilated in } \\
\text { Laboratory }^{6}\end{array}$} & \multirow[t]{2}{*}{$\begin{array}{l}\text { Laboratory } \\
\text { Medium }^{5}\end{array}$} & \multirow[t]{2}{*}{$\begin{array}{c}\text { Laboratory } \\
\text { Medium }^{7}\end{array}$} & \multirow[t]{2}{*}{$\begin{array}{l}\text { Laboratory } \\
\text { Medium }^{8,9}\end{array}$} & \multirow[t]{2}{*}{$\begin{array}{l}\text { Téboulba Harbour } \\
\text { Tunisia, assimilatec } \\
\text { in Laboratory }\end{array}$} \\
\hline & & & & & & & \\
\hline Species(s) & Abysochormene distintus & Gammarus fossarum & Gammarus fossarum & Daphnia pulex & Daphnia pulex & Daphnia manga & Carcinus maenas \\
\hline Contaminant(s) & Copper & Copper & Cadmium & Cadmium & $\mathrm{ZnO}$ (NPs) & Copper & $\begin{array}{l}\text { Contaminated } \\
\text { sediment }\end{array}$ \\
\hline Cuticle & $\uparrow$ & & & $\uparrow$ & & $\downarrow$ & $\uparrow$ \\
\hline Chitinase & $\downarrow$ & - & - & $\downarrow$ & $\downarrow$ & $\downarrow$ & $\downarrow$ \\
\hline $\mathrm{Na}+/ \mathrm{K}+$-transporting ATPase & $\uparrow$ & - & - & & & & \\
\hline Metalloendopeptidase & $\uparrow$ & & & & & & \\
\hline mitochondrial ATP synthase subunit alpha & $\uparrow$ & - & & & & $\uparrow$ & \\
\hline elongation factor 1 Alpha & $\uparrow$ & - & & & & & \\
\hline RNA-dependent RNA polymerase & $\uparrow$ & & & & & & \\
\hline GMP synthase & $\uparrow$ & & & & & & \\
\hline $60 \mathrm{~S}$ ribosomal protein & $\uparrow$ & & & & & & \\
\hline mitochondrial 39S ribosomal protein L30 & $\uparrow$ & & & & $\uparrow$ & & \\
\hline blastula protease 10 -like & $\downarrow$ & & & & & & \\
\hline cathepsin D & $\downarrow$ & & & & & & \\
\hline chymotrypsin A-like & $\downarrow$ & & - & & & & $\downarrow$ \\
\hline $\begin{array}{l}\text { di-N-acetylchitobiase precursor } \\
\text { chitotriosidase-1 }\end{array}$ & $\begin{array}{l}\downarrow \\
\downarrow\end{array}$ & & & & & & \\
\hline Carboxypeptidase B & $\downarrow$ & & & & & & $\downarrow$ \\
\hline Heat shock protein 70 & $\downarrow$ & & & & & & $\uparrow$ \\
\hline Ferritin & $\uparrow$ & & & $\uparrow$ & & $\downarrow$ & \\
\hline NADH dehydrogenase & $\uparrow$ & - & & & & $\downarrow$ & \\
\hline $\begin{array}{l}\text { Glutathione peroxidase } \\
\text { lectin domain family } 4 \text { member } F\end{array}$ & $\downarrow$ & & & $\uparrow$ & $\uparrow$ & $\begin{array}{l}\downarrow \\
\downarrow\end{array}$ & \\
\hline
\end{tabular}


Figure S1.

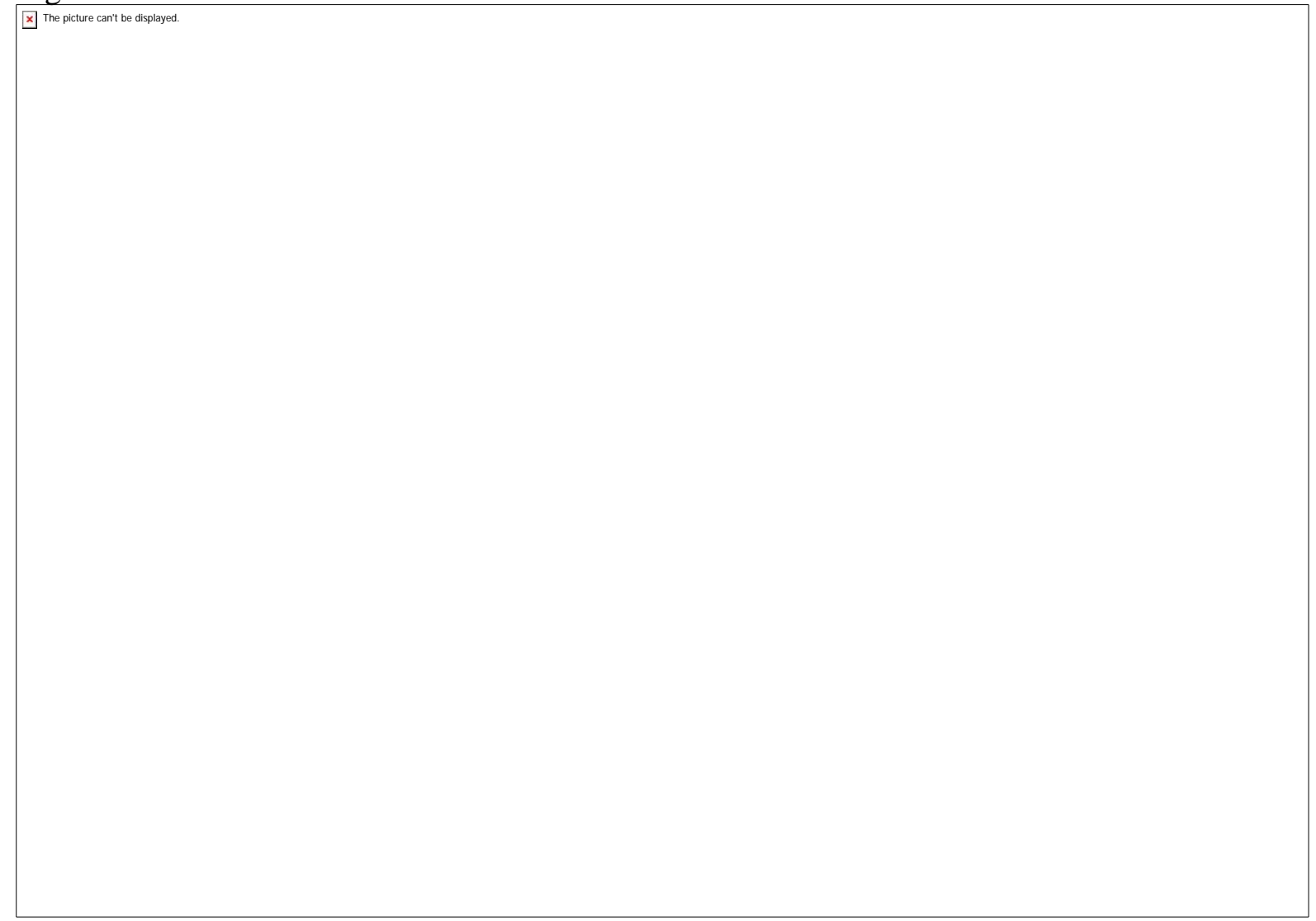

The schematic diagram of lander with bait trap set-up. The diagram illustrated the bait trap adopted in a deep-sea lander set-up that used during the experimental sampling for copper exposure on deep-sea amphipods. 
Figure S2.

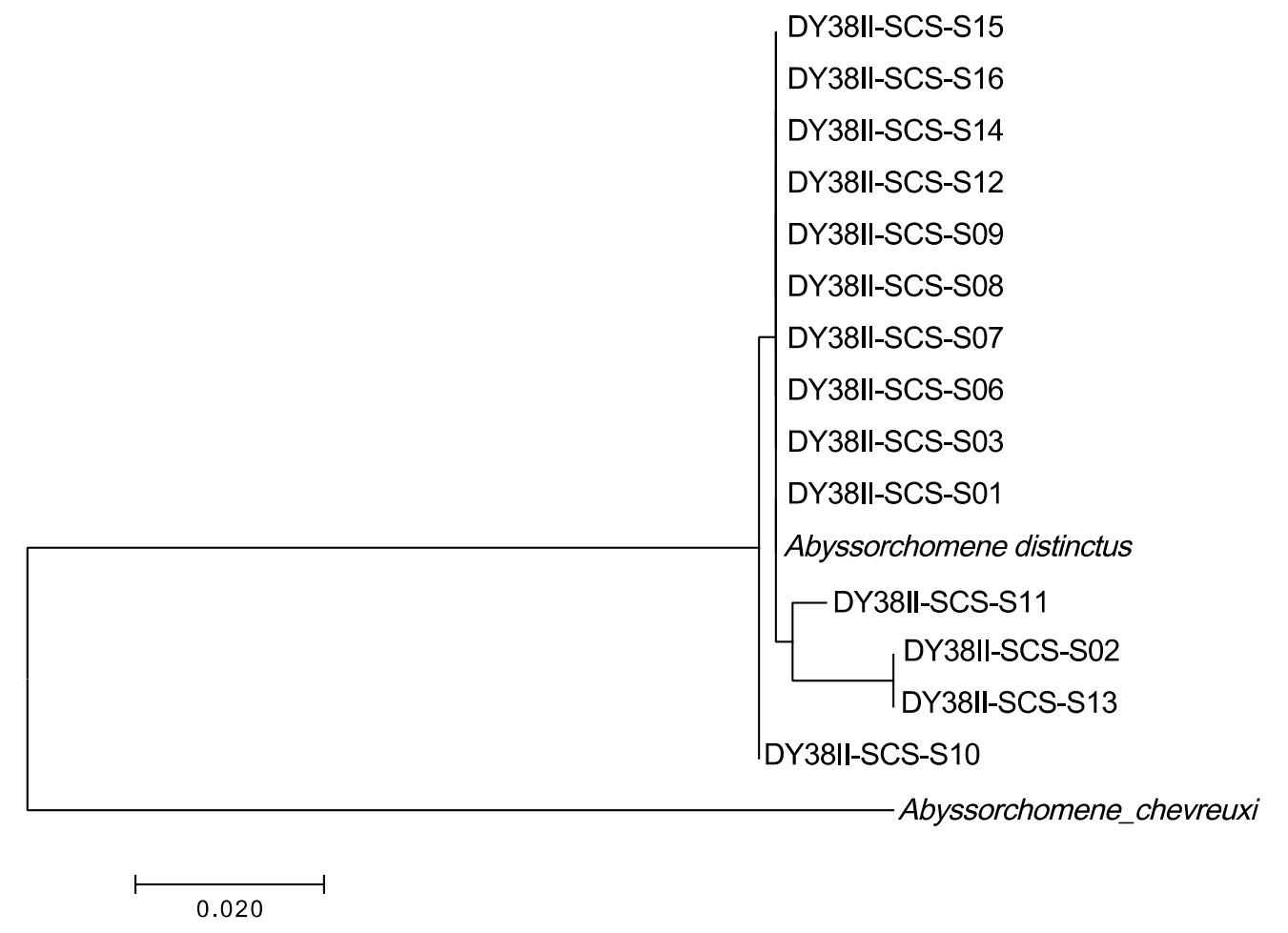

The phylogenetic tree of $A$. distinctus using Cytochrome c oxidase subunit I (COI). The COI sequences were aligned, and followed by computing a best model test in MEGA 7 for each orthologue genes. A Maximum-Likelihood tree was then constructed with General Time Reversible model and Gemma distributed with Invariant sites, with a bootstrap value of 1000 . 
Figure S3.

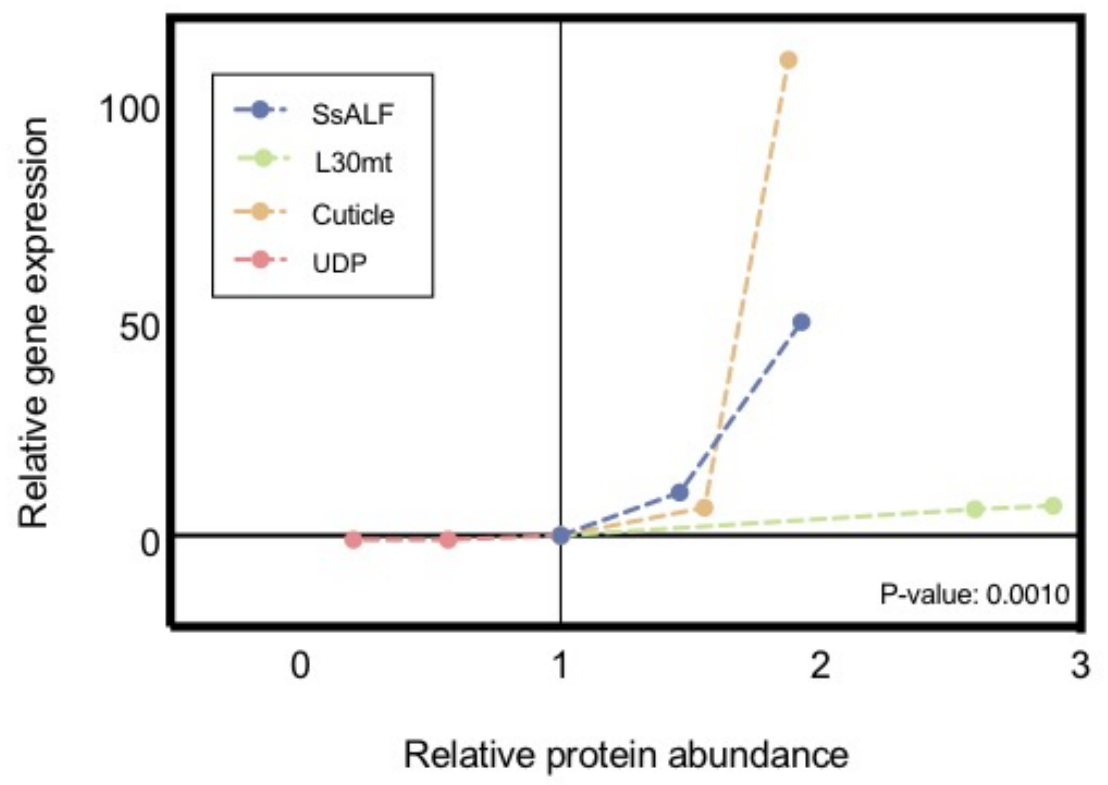

qPCR validation result. This graph illustrated the qPCR result of 4 different genes with their respected protein abundance detected in the LC-MS/MS protein intensity. It confirmed that the expression of the corresponding genes is up-/down-regulated, explaining the abundance of the proteins observed by proteomics. 